\title{
Review
}

\section{Thinking like a Mall: Environmental philosophy after the end of nature}

\author{
Steven Vogel \\ MIT Press, Cambridge, MA, 2015, x+296pp. ISBN: 9780262529716
}

Contemporary Political Theory (2017) 16, 549-552. doi:10.1057/s41296-016-0075-x; advance online publication 23 September 2016

Thinking Like a Mall offers a clear and thoughtful path through postnaturalist environmental philosophy. Vogel builds a powerful argument for why we need to move forward with environmental philosophy without a special category of nature. In asserting that humans co-engineer the environment with other beings, he places humans in a position to take responsibility for their impacts. Vogel skillfully makes a case for collective responsibility through deliberative democracy that does not depend on a particular conception of nature. One of the most impressive contributions of this book is maintaining a strong connection between a philosophy of postnaturalism and political engagement. Vogel asks us to use our special capacities as humans as the basis for acting responsibly, rather than claiming that these capacities are entitlements to create a bad environment.

Vogel begins by dismantling two concepts of nature that dominate environmental thought. He addresses McKibben's (1989) claim that humans have so thoroughly defiled the natural world that there is not any untouched nature left. Starting from J.S. Mill, Vogel works out the logical conclusion of two views of nature: (1) Defining nature as everything in the world, and (2) nature as everything except for humans. Vogel concludes that both versions of "nature" are insufficient as the basis for modern environmentalism, by demonstrating the fruitlessness of trying to make real distinctions between the artificial and the natural. There was never a "real" or "first" nature to begin with, and from this point we develop a postnatural environmental philosophy that takes care to think about our environs instead of the nature/culture dualism.

With a foundation for postnaturalism, Vogel presents his view of the social construction of nature, informed by Marx's materialism. In a literal sense, nature is socially constructed by practices that humans and more than human forces together constitute over time, sometimes on purpose, sometimes accidentally, and always with unanticipated effects. Remembering that construction is a physical process helps us to overcome the nature/human dualism, and reminds us that practice is what makes the world, from knowledge production to objects. If human labor

(C) 2016 Macmillan Publishers Ltd. 1470-8914 Contemporary Political Theory Vol. 16, 4, 549-552 www.palgrave.com/journals 
makes the environs, then Marx's theory of alienation applies to the relation between humans and the environment. If we are detached from that which we built, then we are unable to take responsibility for those things. Alienation from one another precludes the possibility of socially constructing a world in which we can be collectively responsible, and consciously designing.

In order to consciously design, Vogel questions the conventional wisdom that artifacts are human-made and therefore outside of nature. The gap between the construction of the artifact and the intention of the builder is full of forces that may or may not have been set in motion by the builder, but which the builder relies on to create the artifact. These forces are not fully known to us, from gravity to chemical reactions to chance. There is independence in everything that is human built. He uses this study of artifacts to direct us toward two virtues: The first is selfknowledge, which is to see our entanglements in the co-constituted world. The other is humility, which seems especially important as a way to temper the glimmers of techno-optimism that one might find if we leave nature behind and see ourselves as capable of making the world. Without these virtues, one could take up the emphasis on human activity to rationalize the kind of green capitalism and geoengineering that I suspect runs against Vogel's stated concern for practicing environmentalism in the economic, rather than political, sphere.

We eventually wind up, like so many Americans, at the mall. The mall is typically regarded as a symbol of artificiality and consumerism, which makes it a provocative illustration of Vogel's case for total entanglement between humans and environment. The mall is no different from other objects that are made by human and nonhuman forces and with a life that exceeds the intention of the builders. If there is intrinsic value in the things that we make, given that those things are never exclusively human-made, then we can see ourselves as responsible for those things, which is to say, "it should matter to us what happens to them" (p. 164). Even the mall should matter to us. How we work out responsibility brings us into the political sphere.

Humans are not just responsible for what they have built, but for deciding together how to build an environment. For Vogel, humans are unique in two important ways: They possess dialogic language, and they have a sphere of politics. Dialogical language is a precondition for engaging in politics. A serious argument here is that "questions of ethics arise in language, and must be resolved in language" (p. 170). A speech act can be true or false, and it is subject to criticism and justification. One school of thought - perhaps he is referring to deep ecology insists that nature speaks, but we do not listen. Following Vogel's argument, nature does not speak, at or least "not in a way that has ethical implications" (p. 183). If our relation with the nonhuman is nondialogical, then it is nonreciprocal, and does not count as speech. When translators or storytellers make normative claims that come from nature, they are buffered from taking responsibility because they are speaking for the other. It is clear that Vogel finds nature silent. The argument does 
not exclude the nonhuman from moral consideration, but it does mean that only humans get to decide what that means.

Following from the assumption that humans are uniquely responsible for setting the standards of moral consideration, Vogel turns toward democracy and managing the commons. One of the reasons collective responsibility is appealing is because people do not intend to create environmental harms, so tracing individual causality will not produce good environmentalism. People might be cavalier about environmental harms, but the purpose of mining is not a sludge pond break. Instead of looking to nature to provide a normative standard for action, environmentalists need to build that standard collectively, which is to fully take responsibility.

While the book brilliantly puts forward an argument for thinking of the environment in terms of entanglement, the turn toward democracy leaves some unresolved questions. Vogel argues that language-based communication is a prerequisite for joining a political community. However, there is a growing body of research that describes complex communication among other animals. Animal intelligence has been poorly recognized by the limited ways in which humans have studied other beings. Humans study the language of mammals, and have spoken with primates using sign language. Birds from the corvid family, along with other animal societies, have methods of conflict resolution and social orders, all of which are considered political actions in human societies. I do not know if a political community should be exclusive to those who can engage us dialogically, but this position seems at odds with the rest of Vogel's interest in entanglements. If dialogical language is a prerequisite for joining a political community, then we should be prepared to include more beings than we anticipated.

Another exclusion is of people who profess to communicate with the more than human world. In asserting the impossibility of this task, Vogel inadvertently sweeps up many indigenous epistemologies as one of many with fraudulent claims of directly communicating with the more than human. Perhaps it is the limited vision of western philosophy that makes it seem unfathomable to have reciprocal communication with other living beings. Instead of adding more barriers to political engagement, Vogel's interest in interconnection could be used to support a diversity of epistemologies in a political community. Vogel's overarching argument calls for us to do the work of figuring out what constitutes good engagement with the environment, and this can be an invitation to learn from other epistemic approaches, rather than to dismiss.

Vogel's political community is rooted in an ideal of democracy that will need to engage power relationships and responsibility. For example, it is unclear to me how this approach would handle a sticky issue like uranium pollution on Navajo land (LaDuke, 2009). The model does not have a clear mechanism for dealing with the uneven power dynamics between a colonized and colonizing power, the intergovernmental relations that are a product of colonization, and the differences between Navajo and colonial-settler epistemologies. Perhaps included in a theory

(c) 2016 Macmillan Publishers Ltd. 1470-8914 Contemporary Political Theory Vol. 16, 4, 549-552 
of collective responsibility is consideration for how deliberative democracy takes place in a web of particular relations, rather than in some homogenous space of democratic engagement. Vogel's book provides an important bridge between the philosophy of nature and collective responsibility in politics. To arrive at a call for discursive democracy through a postnatural framework is incredibly productive for pushing beyond the long-standing debate over the nature of nature, and will have an enduring impact on how we think about acting responsibly.

\section{References}

LaDuke, W. (2009) Uranium Mining, Native Resistance, and the Greener Path. Orion Magazine, January. Accessed 31 May 2016: https://orionmagazine.org/article/uranium-mining-native-resistanceand-the-greener-path/.

McKibben, B. (1989) The End of Nature. New York, NY: Random House.

Emily Ray

Sonoma State University, Rohnert Park, CA 94928, USA emily.ray@sonoma.edu 